\title{
Interactive Business Models to Deliver Product-Services to Global Markets
}

\author{
Sergio Cavalieri ${ }^{1}$, David Romero ${ }^{2}$, Jan Ola Strandhagen ${ }^{3}$, and Paul Schönsleben ${ }^{4}$ \\ ${ }^{1}$ University of Bergamo, Department of Engineering \\ CELS - Research Group on Industrial Engineering, Logistics and Service Operations \\ sergio.cavalieri@unibg.it \\ ${ }^{2}$ Tecnológico de Monterrey \\ david.romero.diaz@gmail.com \\ ${ }^{3}$ Norges Teknisk-Naturvitenskapelige Universitet (NTNU) \\ jan.strandhagenesintef.no \\ ${ }^{4}$ ETH Zurich \\ pschoensleben@ethz.ch
}

\begin{abstract}
The main aim of this paper is to propose a collaborative solution platform to design, assess and deploy technology-based business models, supporting the analysis and evaluation of business ecosystems for the manufacturing and delivery of customised product-services in global markets. The proposed platform will guarantee a common thread for the execution of a multi-stage gate reference process for the generation and consolidation of a technology-based business model, providing a consistent path from the idea generation to the production, delivery and commercialisation of a solution.
\end{abstract}

Keywords: Business Models, Value Propositions, Emerging Technologies, Global Markets, Product-Service Systems.

\section{Introduction}

To create new sources of value, several industrial sectors are striving to provide integrated product-service solutions, which would contribute to tighten and foster the relationship with the customer. Regardless of the business context, either B2B or B2C, customers ask for products with a high degree of personalisation and with better quality, faster delivery times, and shorter times between successive generations of products. The distinction between products and services, tangible and intangible, is blurring in favour of the elaboration of a more customer-oriented strategy. Breaking down the traditional barriers between products and services, the concept of Product-Service System (PSS) prevails as a systemic approach enabling a strategic and managerial transition from selling a mere artefact to providing the user with a unique and positive experience throughout the journey with a customised and result-oriented solution.

In response to this, manufacturing industry has to change its approach from costcutting to customer-centric knowledge-based value adding through the adoption of innovative business models, aiming at increasing the product variability, customisability, and production robustness. 
The combination of these trends, summarised in Figure 1, is pushing companies to rethink their value creation mechanisms by shifting from a broad global standpoint to a responsive local perspective in order to be perceived by the final customer as a "good and reliable neighbour". These factories of the future need to be collaborative, reconfigurable, adaptive and evolving, capable of small-scale production to create new customised products and services, environmental friendly and able to respond promptly to the uncertain market evolution.

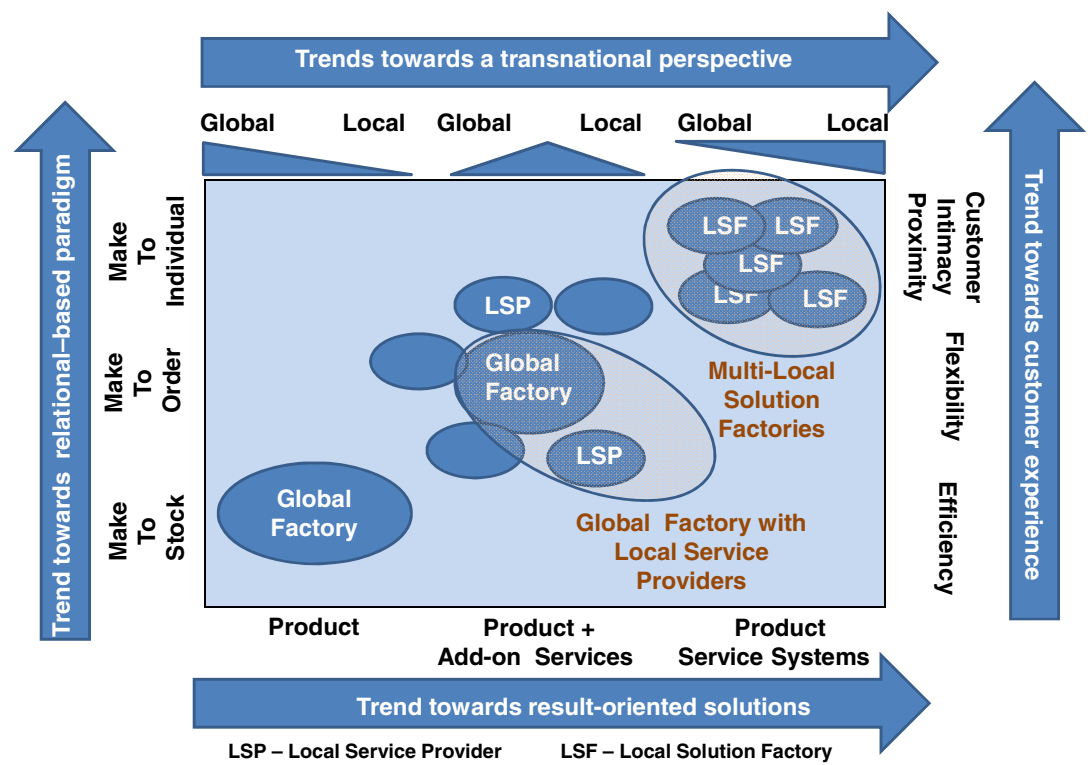

Fig. 1. The Evolutionary Path towards Multiple-Local Solution Factories

Consequently, enterprises are moving from an international business approach, with large and highly specialised global factories, to a transnational strategic positioning, by relying on a multitude of local solution factories (LSF), proximate to the demand and able to provide customised PSS. Such a strategic changeover requires also the dynamic reconfiguration of a constellation of manufacturing companies and solution providers capable to operate at multiple locations around the globe.

To tackle all these challenges and maintain the competitive leadership in different markets, the European Strategy 2020 Agenda stresses the role of technology as the key enabler of flexible and innovation-driven networks. Technology plays an important enabling role in developing value for the society by providing innovative ideas to be turned into new customer-oriented product-service systems and in restructuring industrial processes. However, even if the mastering and deployment of key enabling technologies are expected to provide significant economic benefits, their actual application is still limited and in many cases their commercialisation has not been as successful as expected. According to the EC Working Team on Advanced Manufacturing Systems, it is fundamental to find a consistent way to link innovation policies for key enabling technologies to an industrial policy, which will underpin the 
deployment and further development of advanced manufacturing technologies.

In such a context, the main motivation of this paper resides in the need to rely on a reference process for technology-based business models generation. This would enhance and exploit the opportunities and the potential derived from the introduction and proper hybridisation of emerging technologies in the global production and service contexts.

\section{Business Model Frameworks for Product-Service Systems}

Since the 90s, companies operating in the western mature markets have progressively realised the importance of complementing industrial goods with the provision of value added services, shifting the business focus from selling a physical product to offering functions, services and performance [1]. In exploring this phenomenon, a relevant stream of the literature has assigned an increasing emphasis to the role of ProductService Systems (PSS) as a concrete response to these emerging pressures. The main idea behind the PSS concept is that it ensues from an innovation strategy, moving the business focus from the design and sales of physical products to the design and sales of a system consisting of products, services, supporting networks and infrastructures, which are jointly capable of fulfilling specific client demands [2].

However, although services are thought to deliver higher margins, most organisations find it quite problematic to master this transformation. To properly provide services, they must radically change the way they operate and mature the capability to design and deliver services rather than products and develop new knowledge, organisational principles, metrics and incentives.

In order to ensure a successful implementation of a PSS into the market, proper business models must be identified. A business model is a logical description of how a firm does its business with its products and services [3]. It provides a basis for creation of tools and frameworks to assist business managers and engineers in investigating business models and value propositions. These tools serve a number of potential functions: from capturing and understanding the relevant elements and interactions of a business model to assisting in the design, planning and management of value creation logic, as well as in prospecting business models through structured design and simulation [4]. Along the literature in the last decade, it is possible to find several business model generation processes and reference models. Among them, the most famous one is the business model canvas proposed by Osterwalder and Pigneur [5]. Most of the contributions attempt to establish the taxonomy, architecture, or constituent elements of business models, mostly focusing on the question: "What elements are needed to establish a firm's business model?", whilst neglecting the question: "How is an innovative business model to be designed?"

Among the many factors that support business model innovation, emerging or new technologies have always played a key role, because they can provide a relevant contribution in designing new products and services, in improving product and service quality, and in making a production process more flexible, configurable and economic. Innovation and new initiatives require business model changes at the enterprise level, because if new and emerging technologies are poured into old business models, innovation will not be successful for companies and it will not lead to customer orders and new revenues. 
However, the success or failure of a company's business model depends on how it interacts with the business models of other players in the industry, that are all fighting to create and capture value too. In fact, if analysed in isolation one business model can appear successful, but the interactions with other companies' business models can lead to a failure. Thus, it is important, when developing a business model, to consider the dynamic interactions with all the other players (e.g. suppliers, distributors, customers and even competitors) operating in the business ecosystem ${ }^{1}$ involved in the delivery of a specific product or service that could also lead to turn a rival into a partner in value creation [6].

For this reason, it becomes important to foster collaboration with other partners inside the same industry in order to identify new business opportunities leveraging on cooperation and on the exploitation of new technologies. Besides the lack of external collaboration, one of the main barriers companies have to cope with to provide successful product-service systems is the lack of experience and know-how to design product-service solutions and the related management systems [7].

Compared to physical products, services are still under-designed and inefficiently developed, even if service design and development issues are increasingly being recognised as important to managers [8]. There is the need to design and develop an integrated offering that is valuable to customers in order to contribute to a continuous positive change throughout the journey of experience.

In addition, the creation and successful implementation of PSS business models requires a rethinking of managerial and organisational practices, new capabilities and competencies, as well as an assessment of supply chain relationships, in order to define the level of collaboration among firms, and the intensity and density of interaction and coordination modalities. These elements are crucial for identifying business models tailored to specific contexts. It does not only facilitate market-led initiatives, but also plays a major role in initiating the process of capability building and coordinating the actions of a large number of interested actors.

Furthermore, a fundamental key success factor, especially for manufacturers operating in sectors where market turbulence is higher, is the aptitude to rapidly adapt to unexpected market fluctuations in order to keep customers satisfied. This goal can be achieved by exploiting manufacturing technologies, and ensuring the proper flexibility and reconfigurability levels, that can allow such rapid changes in volumes and features of the produced parts [9].

In such a context, what is needed is a reference process for a technology-based business model generation which could enhance and exploit at best the opportunities and the potential deriving from the introduction and proper hybridisation of emerging technologies in the global production and service contexts. In other words, a structured methodology to translate customer needs into a product-service solution and to provide companies with a product-service oriented reference process supporting its design and development with a systematic perspective and a seamless integration of product and service contents, as well as supply and service chains configurations, and new manufacturing systems engineering.

\footnotetext{
${ }^{1}$ A business ecosystem is a network of organisations - including suppliers, distributors, customers, competitors, and so on - involved in the delivery of a specific product or service through both competition and cooperation.
} 


\section{An Interactive Business Model Framework for PSS}

The main goal of this paper is to propose a collaborative solution platform to design, assess and deploy technology-based business models, supporting the analysis and evaluation of a business ecosystem for the manufacturing and delivering of customised product-services in global markets.

In order to pursue this objective, three are the main assisting means or tools, as highlighted in Figure 2.

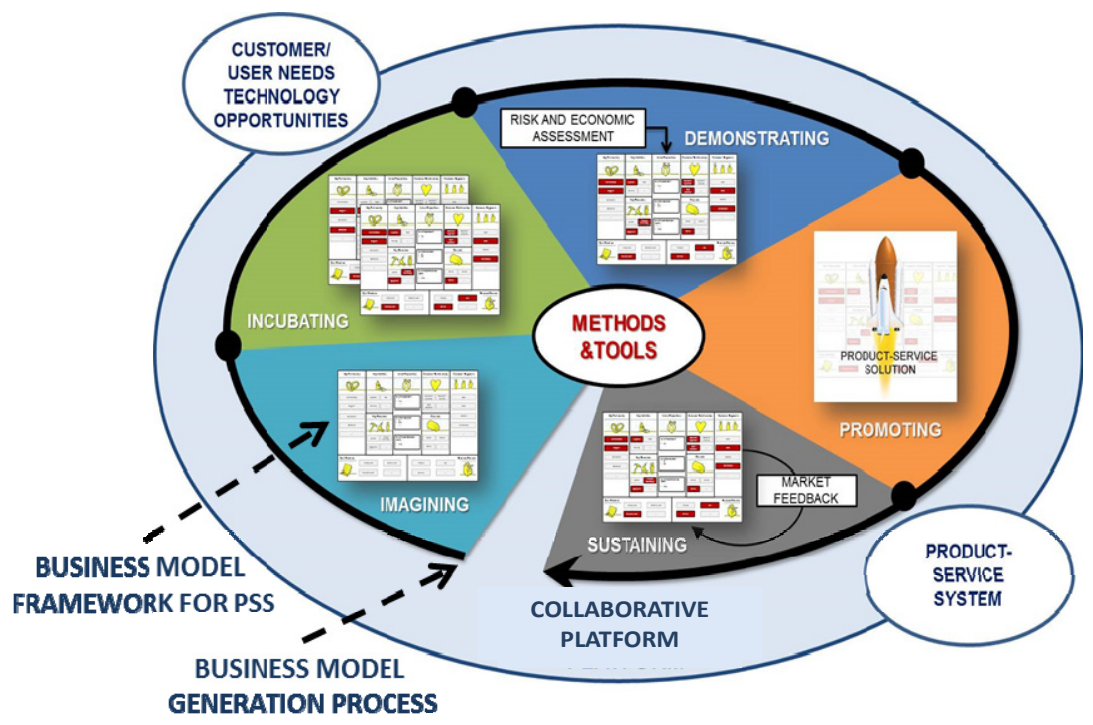

Fig. 2. An Interactive Business Model Framework for PSS

In particular:

- The Business Model Framework: founded on the Business Model Canvas, it contains the main elements of a business model and can be used to describe, analyse and design business models to guarantee a successful implementation of a product-service system in the market.

- The Business Model Generation Process: it is a multi-stage gate reference process for the generation and consolidation of technology-based business models, providing a consistent path from the idea generation to the commercialisation and provision of a product-service solution, particularly addressing the technological contents of the product-service solution and of the manufacturing and assembly systems.

- The Collaborative Platform provides the collaborative IT environment involving the focal actor and the different stakeholders in the creation of a customised business model and in simulating its affordability, robustness and durability throughout the whole lifecycle. 


\subsection{The Business Model Framework for PSS}

The proposed Business Model Framework is based on the Business Model Canvas developed by Osterwalder and Pigneur (2010) [5]. This canvas contains the main elements of a business model and can be used to describe, analyse and design business models. As depicted in Figure 3, it is composed by nine elements: value proposition, customer segments, customer relationships, channels, key activities, key resources, key partners, cost structures, and revenue streams.

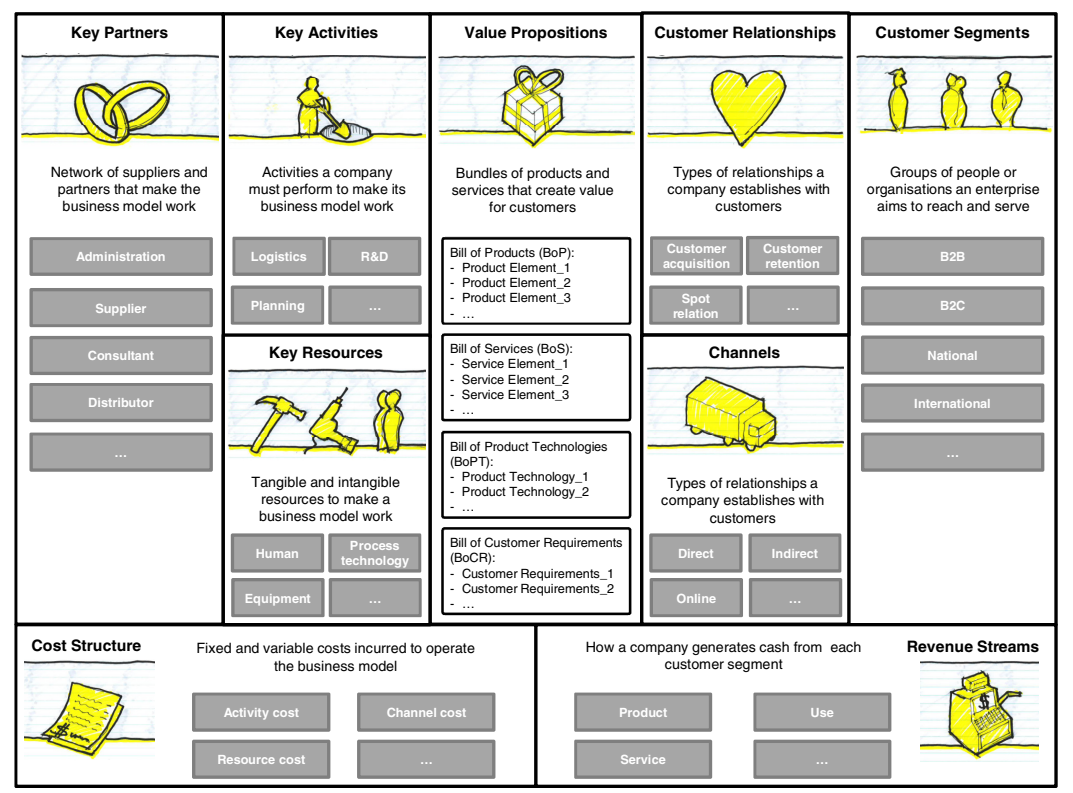

Fig. 3. The Business Model Framework for PSS [Adapted from 5]

This structured business model framework acts as a template/canvas where each element (except the value proposition) consists of predefined building blocks that represent strategic and tactical patterns. An example of a business model framework with the predefined building blocks is depicted in the same Figure 3. The building blocks in the Business Model Framework are devised in such a way that they can represent any PSS business model case (e.g. B2B, B2C). They are generic enough to be combined across the boundaries of various industries so that proven ideas in one business model could be transplanted into another, which is often the case in the real world. By mixing \& matching various building blocks, this Business Model Framework could provide one or more alternative business models that will be then assessed.

An exception is represented by the value proposition element: it would not be composed of building blocks, but designed and defined as the combination of a Bill of Products (BoP), Bill of Services (BoS), Bill of Product Technologies (BoPT), and Bill of Customer Requirements (BoCR). These bills are specific to the company/industry context under analysis, and they will contain all the elementary products, service elements, product technologies and customer requirements that will be the constituent parts and design-drivers of the product-service solution. 


\subsection{The Business Model Generation Process for PSS}

The Business Model (BM) Generation Process proposed is based on the experience of companies implementing successfully PSS Business Models into the market. This BM Generation Process is divided in the following five phases [Adapted from 10]:

1. Imagining: starting from the $\mathrm{BoP}, \mathrm{BoS}, \mathrm{BoPT}$, and $\mathrm{BoCR}$, the objective of this phase is to create the value proposition based on a user-centric approach. The Business Model Framework represents a guideline to support, and to design a PSS business model as a selection of a set of predefined building blocks.

2. Incubating: this phase deals with the product-service engineering, the supply and service chain configuration, and the manufacturing and assembly system configuration.

3. Demonstrating: this phase consists in the definition of economic and risk models to assess alternative product-service systems, in terms of product-service solution, supply and service chain, provision process, manufacturing and assembly system.

4. Promoting: the objective of this phase is to define the most effective marketing strategy to launch the product-service solution into the market and to start its commercialisation.

5. Sustaining: this phase deals with the commercialisation of the product-service solution and with the undertaking of the product-service lifecycle operations.

\subsection{The Collaborative Platform}

The implementation of the Collaborative Platform is crucial for gaining concrete results of this vision. It provides the collaborative environment involving the focal actors and the different stakeholders in the emerging creation of a customised business model and in simulating its affordability, robustness and durability throughout the whole lifecycle. The main distinctive design features of this platform are:

- Supporting a stage-gate process, where "gates" or decision points are placed at specific phases of the business model generation process;

- Acting as a repository of data and information (e.g. searching the best available technologies, the most qualified partners for a specific competence required, etc.), where all the documentation is archived and can be easily retrieved through a knowledge inference engine in order to favour team working and information sharing among cross functional teams;

- Acting as an open technology marketplace in order to encourage collaboration among companies working in different but complementary industries with the aim of creating innovation and providing product-service solutions tailored to customer needs;

- Supporting the elaboration of simulation scenarios and what-if analysis for proactively evaluating the expected technical, risk and economic implications derived from a specific configuration of the business model;

- Embedding a dashboard in its functionality for monitoring the main technical and financial KPIs (Key Performance Indicators) throughout a contract lifecycle in order to enable a prompt understanding of any deviations from expected SLAs (Service Level Agreements) and highlight eventual counter-measures. 


\section{Conclusions and Future Work}

The proposed collaborative platform will enable the adoption of novel value proposition concepts to global markets leading to user-oriented higher value-added solutions, by integrating a service perspective into new or existing products from their conception on; methodologies and tools for the interactive design of alternative technology-based business models, with particular emphasis on the co-evolution from the early design stage of product-services and their production systems and delivery processes based on global partner networks for worldwide markets; and methodologies and tools for the assessment of the key economic and risk factors involved in the designed product-service ecosystem, in particular for the integration of new complex production technologies and global partner networks.

This assessment will be based on interactive and model-based decision-making processes, able to evaluate the impact derived from the introduction of emerging technologies and the performance of alternative configurations of the actors involved in the global partner network providing product-services into the worldwide market.

\section{References}

1. Sundin, E., et al.: Integrated Product and Service Engineering Methodology. In: Proceedings of 11th International Conference of Sustainable Innovation, Chicago, USA (2006)

2. Cavalieri, S., Pezzotta, G.: Product-Service Systems Engineering: State of the art and research challenges. Computers in Industry 63(4), 278-288 (2012)

3. Lee, J.H., Shin, D.I., Hong, Y.S.: Business Model Design Methodology for Innovative Product-Service Systems: A Strategic and Structured approach. In: Annual SRII Global Conference, pp. 663-673 (2011)

4. Osterwalder, A., Pigneur, Y.: Clarifying Business Models: Origins, Present, and Future of the Concept. Communications of the AIS 15 (2005)

5. Osterwalder, A., Pigneur, Y.: Business Model Generation: A Handbook for Visionaries, Game Changers, and Challengers. John Wiley \& Sons, Inc., Hoboken (2010)

6. Romero, D., et al.: Towards the Definition of Business Models and Governance Rules for Virtual Breeding Environments. In: Network-Centric Collaboration and Supporting Frameworks. IFIP, vol. 224, pp. 103-110. Springer, NY (2006)

7. UNEP - Division of Technology, Industry and Economics: The Role of Product Service Systems in a Sustainable Society, http://www.uneptie.org/scp/design/ pdf/pss-brochure-final.pdf

8. Menor, L., et al.: New Service Development: Areas for Exploitation and Exploration. Journal of Operations Management 20, 135-157 (2002)

9. Copani, G., Urgo, M.: New Business Models and Configuration Approaches for focusedflexibility Manufacturing Systems. In: 1st CIRP Global Web Conference: Interdisciplinary Research in Production Engineering (2012)

10. Jolly, V.: Commercializing New Technologies: Getting from Mind to Market. Harvard Business School Press (1997) 